\title{
TAFOFLORULA MONTE MOR DO ESTADO DE SÅO PAULO: SEUS ELEMENTOS E SEU SIGNIFICADO NO GONDWANA INFERIOR DO BRASIL
}

\author{
JOSE HENRIQUE MILLAN*
}

\begin{abstract}
A study of the Monte Mor florula (Itu Formation, Tubaråo Group in the State of Săo Paulo indicates that it is composed of gondwanic elements "mixed" with other boreal and cosmopolitan genera.

Association of arborescent Lycopsida and Sphenopsida with Botrychiopsis, Rhacopteris, Adiantites, etc., and complete absence of Glossopterids point out a general Carboniferous age for the flora, posibly Westphalian-Stephanian. The same age was deduced by Trindade (1970).

Ocurrence of $\mathrm{cf}$. Leaia and eurypterid associated with Lepidodendron, Lycopodiopsis, Paracalamiles, Sphenopteris and numerous seeds Cordaicarpus and araucaroid conifers such as Paranocladus may signify a lacustrine environment for deposition of plant fragments and, possibly, formation of Monte Mor coal beds. The state of preservation of megaplants showing decorticated stems corroborates this idea, since they are indicative of short transportation of the plant fragments and at least a semi-autoctone origin for the coal beds.

The mixture of boreal and cosmopolitan elements in the Monte. Mor taphoflorula could be explained by the existence of a zonal paleoclimatic differentiation during the Upper Carboniferous, leading to the migration of pioneer elements toward nearby continental masses.
\end{abstract}

INTRODUÇÃO A presente contribuição corresponde, em linhas gerais, aos capítulos dedicados ao confronto com outras tafoflórulas, às implicações paleoecológicas e às conclusões de nossa Tese de Doutoramento (Millan, 1972a), apresentada no Instituto de Geociências da Universidade de São Paulo.

$\mathrm{Na}$ mesma, expõem-se os resultados obtidos no estudo paleontológico realizado nos sedimentitos neopaleozóicos do afloramento Sítio da Mina, Município de Monte Mor, Estado de São Paulo.

A região investigada oferecia particular interesse para a realização desse estudo porque ali foi noticiada (Barbosa e Almeida, 1949) a existência de uma tafoflórula, na capa da camada de carvão, que nunca foi descrita ou ilustrada. Segundo os mesmos autores, tanto na lapa como na capa do carvão, existem restos de peixes paleoniscídeos que se incluem em duas espécies diferentes, uma das quais provavelmente pertencente ao gênero Elonichthys.

No afloramento, que corresponde à quase totalidade da capa da camada de carvão, as camadas fossilíferas forneceram vegetais, incluindo impressões de megásporos Trileites sp. (Fig. 1), e restos de animais relacionados, apenas, a concostráceos cf. Leaia sp. (Fig. 2) e a euripterídeos cf. Eurypterus sp. (Fig. 3).

Esse afloramento localiza-se, estratigraficamente, em sedimentitos da Formação Itu, Subgrupo Itararé, Grupo Tubarão do Estado de São Paulo (Rocha-Campos, 1972), onde "no meio do pacote, situa-se o carvão de Monte Mor (localidade próxima a Campinas) com espessura de 2 a $5 \mathrm{~cm}$. E capeado por um arenito argiloso com restos de vegetais" (Mendes e Petri, 1971, p. 77). Entretanto todos os fósseis coletados são oriundos das camadas (1) e (3) da capa do carvão, constituídas de folhelho argilo-arenoso, ficando o arenito argiloso, que é afossilífero, restrito às camadas (9) e (11) do afloramento (Fig. 4).

* Departamento de Paleontologia, Museu Nacional, Universidade Federal do Rio de Janeiro, GB, Brasil. Em regime de tempo integral (COPERTIDE/UFRJ) 


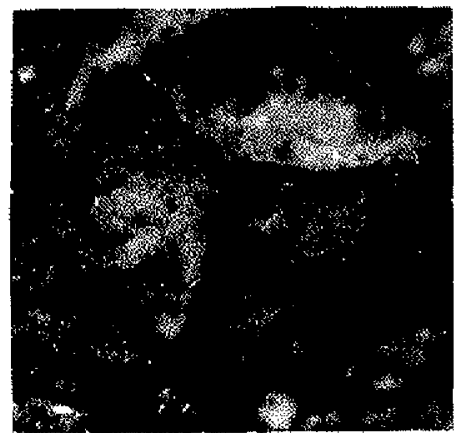

Figura 1 - Impressåo de megásporo Trileites sp. $(30 \times)$, Gol, DP-MN

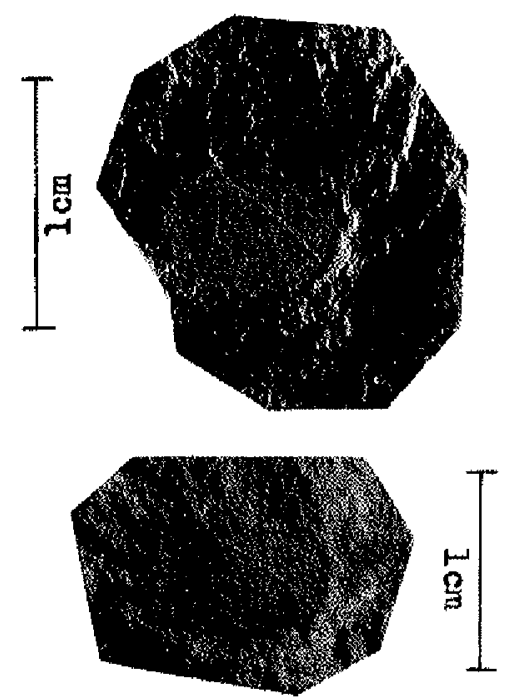

Figura 2 - Impressões de concostráceos cf. Leaia sp., Col. DP.MN

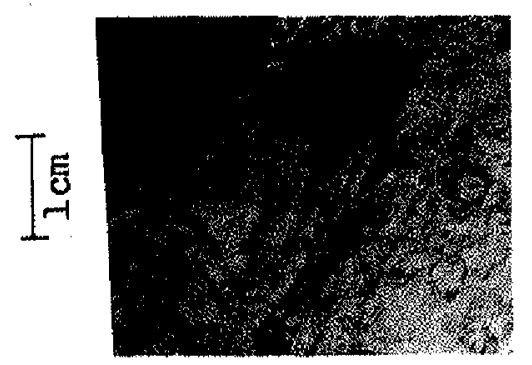

Figura 3 - Impressã̃o de euripídeo cf. Euryterus sp., Col. DP-MN. Assinaladas pelos círculos eståo várias impressões de megásporos Trileites sp.

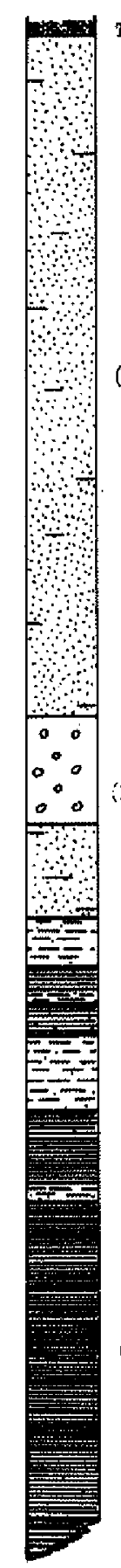

Terra vegetal (solo)

(11) Arenito erg12080, amarelo $(3,00 \mathrm{~m})$

(10) Conglomerado, clnza-amarelado $(0,45 \mathrm{~m})$

(9) Arentto argiloso, cinzamelaro $(0,42 \mathrm{~m})$

(8) Argillto arenoso, clnza-claro $(0,17 \mathrm{~m})$

(7) Folhelho argilo-arenoso, ctnza-amarelado $(0,12 \mathrm{~m})$

(6) Argilito axenoso, cinza-elaro $(0,06 \mathrm{~m})$

(5) Folhelho argilo-arenoso, clma-amarelado $(0,12 \mathrm{~m})$

(4) Argilito Erenoso, cinza-claro $(0,35 \mathrm{~m})$

(3) Folihelho argilo-arenoso, amaralo $(0,30 \mathrm{~m})$. Fossiliffero

(2) Argilito arenoso, cinza-clero $(0,04 \mathrm{~m})$

(1) Follhelho argllamarenoso, chocolate $(1,50 \mathrm{~m})$. Pouco fossilfero.

Figura 4 - Perfil do afloramento Sítio da Mina 
Relação dos fósseis Os restos vegetais têm sua frequêencia relativa na Col. DP.MN, $\mathrm{Pb}$ (Coleção Paleobotânica do Departamento de Paleontologia do Museu Nacional), indicada como segue: (r) rara, três espécimes ou menos; (nc) não-comum, até seis espécimes; (c) comum, mais de seis espécimes e são os seguintes:

\section{SPORAE DISPERSAE}

Trileites sp. (c)*

PALAEOPHYLLALES incertae sedis

cf. Ginkgophyllum sp. A (r)***

LEPIDODENDRALES

Lepidodendron pedroanum Zeiller emend. Millan ( $\mathrm{r})^{* *}$

Lycopodiopsis sp. A (r)***

L. pedroanus (Carruthers) Edwards emend. Kräusel (c)**

L. derbyi Renault (nc)**

SPHENOPHYLLALES

Sphenophyllum sp. A (nc)**

EQUISETALES incerlae sedis

Paracalamites australis Rigby (c)**

$P$. cf. levis Rigby (r)***

$P$. montemorensis Millan, sp. nov. (nc) ****

GENEROS-FORMA incertae sedis

Sphenopteris sp. A (r)**

Adiantites $\mathrm{sp}$. (r)***

Rhacopteris cf. chubutiana Archangelsky e Arrondo (r)***

$R$. cf, ovata (McCoy) Walkom (r)***

Botrychiopsis cf. plantiana (Carruthers) Archangelsky e Arrondo (r)**

?B. cf, weissiana Kurtz emend. Archangelsky e Arrondo (r)***

CORDAITALES

Noeggerathiopsis hislopii (Bunbury) Feistmantel (nc)**

CONIFERALES

Paranocladus? fallax Florin (c)**

Buriadia heterophylla (Feistmantel) Seward e Sahni emend. Pant e Nautiyal (r)**

SEMENTES PLATISPERMICAS incertae sedis

Cordaicarpus nitens (Feruglio) Millan, comb. nov. (c)***

C. barbosanus Millan, sp. nov. (r)***

Samaropsis seixasii (White) Seward (r)**

Confronto com outras Tafoflórulas Barbosa (1958) admite, para a Tafoflorula Monte Mor, idade viseana, pela associação de Lepidodendropsis,? Triphyllopteris e Rhacopteris que ali ocorreria.

Comparando as formas por nós descritas com outras do Carbonífero da Austrália, Argentina, fndia, Peru e Brasil (Archangelsky, 1965, p. 260), verificamos que, dos 21 gêneros mais característicos do Carbonífero Inferior, somente 6 ocorrem em Monte Mor: Adiantites, Cordaicarpus, Lepidodendron, Noeggerathiopsis, Rhacopteris e Sphenopteris. Com exceção de Noeggerathiopsis, todos ocorrem na Austrália, que apresenta o Carbonífero melhor conhecido do Gondwana e que, para alguns autores, divide-se em duas tafoflórulas: inferior, de Lepidodendron veltheimianum, e superior, de Rhacopteris, onde não há mescla com Glossopteris. Segundo Archangelsky a idade do Carbonifero Inferior, pelo menos para a de Rha-

* Ocorrem como impressões e, assim conservados, pela primeira vez no Grupo Tubarão do Estado de São Paulo

**Espécies descritas e figuradas, pela primeira vez, no Grupo Tubarão do Estado de São Paulo

***Espécies descritas e figuradas, pela primeira vez, no Gondwana Inferior do Brasil 
copteris, não tem base segura, já que os invertebrados marinhos, presentes nas mesmas formações, estão indicando uma idade mais recente.

Na Argentina, em comum com Monte Mor, ocorrem 5 gêneros, fazendo exceção Cordaicarpus. Archangelsky, em 1965, admitia para o Carbonífero argentino um panorama desolador, já que as espécies estudadas eram poucas e a revisão, tão necessária para esclarecer problemas nomenclaturais encontrados nos trabalhos de Frenguelli, Szajnocha e Kurtz, não tinha sido efetuada. Cuerda et al. (1968, p. 269) opinam: "No obstante los trabajos ya realizados sobre el Carbonífero en la Argentina, se requierem todavia nuevos estudios estratigráficos y paleontológicos de detalle que permitan establecer una secuencia cronoestratigráfica adecuada para una correlación ulterior con otras partes del mundo".

Aos poucos, entretanto, os vegetais da Coleção Kurtz estão sendo revisados (Archangelsky e Arrondo, 1971 a; Arrondo, 1971) e novas formas estão sendo descritas (Archangelsky e Leguizamon, 1971), porém com dados insuficientes para qualquer correlação mais segura com as formas de Monte Mor.

$\mathrm{Na}$ India, em comum com Monte Mor, ocorre apenas Rhacopteris. Para Archangelsky (1965), a idade da Série Po como Carbonifero Inferior não tem base segura, já que seus restos fragmentários não são indicadores de qualquer associação típica.

No Peru, em comum com Monte Mor, ocorrem apenas 3 gêneros: Adiantites, Rhacopteris e Sphenopteris. À exceção de Rhacopteris (que é uma forma não-comum), os demais são raros em Monte Mor e não constituem uma associação significativa.

Finalmente, no Brasil, na Formação Poti ocorrem em comum apenas 3 gêneros: Adiantites, Cordaicarpus e Sphenopteris e, a nosso ver, desprovidos de um interesse imediato de correlação, pois, à exceção de Cordaicarpus, são raros na Tafoflórula Monte Mor. Abandona-se, portanto, com base nos macrofósseis vegetais, a idade viseana sugerida para essa associação florística da Formação Itu.

Para Rigby (1970, p. 583-584, Tab. 1), das 79 espécies conhecidas na bacia do Paraná, somente 12 existem em comum com as 63 espécies conhecidas na Argentina e nas Ilhas Falkland e relacionadas por Archangelsky (1968).

De acordo com o mesmo autor, há somente 16 espécies em comum entre a bacia do Paraná e o Gondwana da Índia, onde, segundo Surange (1966), existem 163 espécies, e o Gondwana da Austrália, onde 93 espécies são conhecidas.

Esses números, aparentemente, tornam a comparação entre a flora gondwânica do Brasil e a dos países mencionados praticamente impossível. Aliás, Rigby (1970, p. 580) usa esse argumento quando diz: "The lack of species in common between the Paraná basin and Argentina suggests that the floras in the different basins were developing at different rates and in different directions, and free interchange of species was either difficult or impossible; hence the use of these plants for stratigraphic correlation between these two countries is also difficult or impossible". O mesmo argumento é usado para India e Austrália, quando, na mesma página, diz: "Both countries are remote from South América, thus a close relationship need not be expected".

Cremos ser esse um ponto discutível porque, para tal conclusão, são necessários, entre outros, dados fornecidos pelos macro e microfósseis.

Entretanto Daemon e Quadros (1970, p. 363), por exemplo, após o exame das formas de palinomorfos dos intervalos G e H da bacia do Paraná, propostos para o estabelecimento da coluna bioestratigráfica do Gondwana nessa bacia sedimentar, concluem que as mesmas "... são equivalentes àquelas dos andares Talchir e Karharbari da Índią".

Também, segundo Rigby (1970, p. 580), a tafoflora da bacia do Paraná é "... essentialy uncontaminated by extra"Gondwana elements", o que está em flagrante contradição com os conhecimentos atuais que temos dos macro e microfósseis da Formação Itu, carac- 
terizada por uma flórula pré Glossopteris, onde elementos boreais e cosmopolitas "misturam-se" com elementos gondwânicos.

Das 21 espécies descritas na Tafoflórula Monte Mor 9 ocorrem restritamente na bacia do Paraná: Adiantites sp., Cordaicarpus barbosanus, cf. Ginkgophyllum sp. A, Lycopodiopsis sp. A, L. derbyi, Paranocladus (?) fallax, Paracalamites montemorensis, Samaropsis seixasii e Sphenophyllum sp. A.

Considerando as outras 12 espécies não-restritas, observamos o seguinte: Buriadia heterophylla, ocorre nas tafoflórulas do Brasil, India e Antártida; Botrychiopsis plantiana, ocorre nas do Brasil, da Argentina, da India e da África do Sul; B. weissiana, ocorre nas do Brasil (cf.), da Argentina, da Austrália e da India (?); Cordaicarpus nitens, ocorre nas do Brasil e da Argentina; Lepidodendron pedroanum, ocorre nas do Brasil e da Argentina; Lycopodiopsis pedroanus, ocorre nas do Brasil, da Argentina e da Austrália; Noeggerathiopsis hislopii, ocorre em quase todas flórulas gondwânicas, fazendo exceção as Ilhas Falkland; Paracalamites australis, ocorre nas do Brasil, da Índia, da Argentina, da Austrália e da Antártida; $P$. levis, ocorre nas do Brasil (cf.) e da Austrália; Rhacopteris chubutiana, ocorre nas do Brasil (cf.) e da Argentina; $R$. ovata, ocorre nas do Brasil (cf.), da Argentina e da Austrália; Sphenopteris sp. A, ocorre nas do Brasil e da Argentina.

Verificamos, então, que todas as espécies descritas distribuem-se por 5 gêneros tipicamente gondwânicos: Lycopodiopsis, Botrychiopsis, Noeggerathiopsis, Paranocladus e Buriadia; por 2 gêneros caracteristicamente boreais: Ginkgophyllum e Lepidodendron; e por 7 gêneros cosmopolitas: Sphenophyllum, Paracalamites, Sphenopteris, Adiantites, Rhacopteris, Cirdaicarpus e Samaropsis. Os gêneros cosmopolitas, à exceção de Cordaicarpus e Paracalamites, são raros em Monte Mor.

Segundo Archangelsky (1965), Sphenopteris é de valor estratigráfico nulo; Adiantites caracteriza, geralmente, uma associação tipicamente carbonífera, juntamente com Triphyllopteris, Rhacopteris e as Lycopsida e Sphenopsida arborescentes; Rhacopteris, na Europa, é encontrado tanto no Garbonífero Inferior como no Superior, sendo muito arriscada qualquer correlação segura com base numa relativa abundância dessa forma num estrato. Um exemplo desse fato é a mescla de Rhacopteris com Glossopteris, Gangamopteris e Asterotheca na Tafoflórula Chubut (Argentina), cuja idade, em conjunto, é do Permiano Inferior e seus níveis basais, pela presença de Rhacopteris, podem pertencer ao Carbonífero Superior.

Dentre os gêneros gondwânicos, Lycopodiopsis e Paranocladus são abundantes em Monte Mor e, juntamente com Buriadia e Botrychiopsis, que são raros, constituem uma associação que não admite uma idade mais antiga que base do Carbonífero Superior.

A presença de Botrychiopsis é muito importante porque é um vegetal tipicamente austral e porque representa uma forma de relativa antiguidade, tendo atualmente grande valor estratigráfico. No Gondwana do Brasil, até agora, sua ocorrência como Gondwanídium era conhecida apenas no Estado do Rio Grande do Sul, nas localidades Arroio dos Cachorros, bacias dos rios Candiota e Jaguarão e Acampamento Velho, todas dó Subgrupo Itararé do Grupo Tubarão desse Estado, ocorrendo sempre em associação com as Glossopterídeas.

Esse vegetal tem sido encontrado, também, no Gondwana da Argentina, da Austrália, da África do Sul e da Índia e, fora do Gondwana, na Flora de Angara (Sibéria).

$\mathrm{Na}$ Argentina, segundo Archangelsky e Arrondo (1971b), ucorrem duas espécies de Botrychiopsis: B. weissiana, que caracteriza a Idade-Flora Tupense (Westfaliano), e B. plantiana, que caracteriza as Idades-Floras Trampeaderense (Estefaniano) e Lubeckense A (Sakmariano e Artinskiano).

Para esses autores, $B$. wetssiana ocorre, também, no Westfaliano da Austrália e da India (duvidosamente) e B. plantiana do Estefaniano ao Artinskiano do Brasil e da África 
do Sul. Para o Permiano Inferior da India é relacionada, exclusivamente, a espécie $B$. valida.

$\mathrm{Na}$ Argentina, a espécie $B$. weissiana, na Tupense, ocorre associada, principalmente, com Rhacopteris ovata e Sphenopteridium cuneatum na ausência de Coniferales, Glossopteridales e Sphenophyllales, enquanto $B$. plantiana, na Trampeaderense, ocorre associada com as Vojenowskyales, Ginkgoales, desaparecendo Rhacopteris ovata e Botrychiopsis weissiana, continuando ausentes as Glossopteridales e as Sphenophyllales. Na Lubeckense A, a espécie $B$. plantiana ocorre associada, pela primeira vez, com as Glossopteridales e Sphenophyllales e, ainda, com Rhacopteris chubutiana e abundantes Lycopsida arborescentes.

Em Monte Mor, com base em material fragmentário, as duas espécies de Botrychiopsis, $B$. weissiana (? cf.) e B. plantiana (cf.) ocorrem contemporaneamente e associadas, entre outros elementos, com Rhacopteris cf. ovata, $R$. cf. chubutiana, Coniferales (Paranocladus), Sphenophyllales (Sphenophyllum, Paracalamites), na ausência das Glossopterídeas.

Observa-se, portanto, que essa associação paleoflorística, numa análise relacionada com a ocorrência das duas espécies sul-americanas de Botrychiopsis, parece situar-se numa transição entre as idades Tupense e Trampeaderense argentinas, o que equivale dizer que sua idade estaria a um nível Westfaliano-Estefaniano. Outros fatos parecem sugerir esta conclusão.

A ocorrência de $B$. weissiana, se comprovada futuramente em termos mais definitivos em Monte Mor, juntamente com B. plantiana, sugere uma comprovação das possíveis vinculações entre as espécies de Botrychiopsis, sugeridas por Archangelsky e Arrondo (1971b), que consideram $B$. weissiana como antecessora, provavelmente direta, de $B$. plantiana. Aceitando essa idéia, entendemos que, ao longo dessa filogenia, em que $B$. weissiana caracterizou-se melhor no Westfaliano e $B$. plantiana no Estefaniano-Sakmariano, houve um momento em que essas duas espécies foram contemporâneas.

A Tafoflórula Monte Mor poderia representar esse momento na transição Westfaliano-Estefaniano e é muito significativo o fato de $B$. plantiana ocorrer mais típica e quantitativamente nas bacias carboniferas do Estado do Rio Grande do Sul, na passagem do Estefaniano ao Sakmariano, associada já às Glossopterídeas e na ausência de $B$. weissiana. Do exposto, deduz-se que Botrychiopsis é uma forma de relativa antiguidade e cuja origem se afigura como muito duvidosa.

Para Archangelsky e Arrondo (1971b), somente o gênero Furqueia, do Carbonífero Inferior, poderia estar nessa linha evolutiva, pois apresenta pínulas similares, mas com um sistema de ramificação algo indefinido.

Esses autores, entretanto, não formulam qualquer hipótese sobre o possível centro de gênese e dispersão desse vegetal, no Gondwana, mas apenas citam o fato de que adquirem especial significado os restos fragmentários do Westfaliano da Índia, onde, provavelmente, ocorre B. weissiana.

Segundo Dolianiti (1953, p. 130-131) "Em nenhuma parte do antigo continente Gondwana encontra-se Gondwanidium (Botrychiopsis, observação nossa) em associação a elementos de uma flora pré-Glossopteris, pois, à exceção da Argentina, tanto na fndia como na África do Sul, sua ocorrência é assinalada com o aparecimento dessa flora em seus primeiros estágios". Na Tafoflorula Monte Mor, esse gênero ocorre mesclado com outros elementos gondwânicos e com elementos boreais e cosmopolitas, estando as Glossopterídeas ausentes.

Segundo Harrington (1934, p. 334), “... el Sur del Brasil constituyó, durante la edad Dwyka-Talchir, un centro secundário de evolución y dispersión de la flora de Glossopteris, desde donde se produjeron posteriormente migraciones 'en bulto' hacia Sud África y hacia la Argentina. Varias especies de la flora de Glossopteris pueden considerarse como originarias 
de esta región, entre las que se destacan especialmente Gondwanidium validum e Ottokaria ovalis". Para Dolianiti (1953, p. 131), entretanto, isso não ocorreu em virtude de ser Gondwanidium (Botrychiopsis) considerado como originário de algum elemento Rhacopteris e ". . a flora Rhacopteris não foi, até o presente, assinalada no Brasil". No presente trabalho, assinalamos, pela primeira vez, a ocorrência de Rhacopteris no Brasil $\mathrm{e}$, além do mais, associado a Botrychiopsis.

Se considerarmos a Tafoflórula Monte Mor situada, cronologicamente, na transição Westfaliano-Estefaniano, então-a hipótese de Harrington sai fortalecida no que se refere à espécie $B$. plantiana que alcançou, aparentemente, seu nível estratigráfico mais inferior em Monte Mor, que seria um centro de gênese e dispersão da espécie.

$\mathrm{Na}$ Tafonórula Monte Mor, é evidente a ausência de Glossopteris e Gangamopteris, elementos característicos da Flora Glossopteris do Gondwana Inferior do Brasil, considerada pela quase totalidade dos autores como do Permiano Inferior. Para Archangelsky (1965, p. 258), "Una asociación Carbónica deberá estar constituida entre otros elementos por Licópsidas y Sfenópsidas arborescentes junto a Rhacopteris, Adiantites, etc.". Em outras palavras, todos os níveis sem Glossopteris e Gangamopteris pertenceriam ao Carbonífero.

Qualquer que seja a idade da nossa Tafoflora Glossopteris a Tafoflórula Monte Mor será sempre mais antiga, pela associação de Rhacopteris e Botrychiopsis e na ausência das Glossopterídeas.

Até o momento, nossa argumentação baseou-se, essencialmente nos macrofósseis vegetais da capa da jazida de carvão, que tivemos oportunidade de descrever e figurar. Entretanto valemo-nos agora dos estudos de Trindade (1970) sobre os palinocênios do carvão Monte Mor.

Foi verificada, nesse carvão, a presença dos seguintes gêneros de megásporos: Trileites, Lagenoisporites, Calamospora, Duosporites e Setosisporites. Dos gêneros enumerados, ao que parece, somente Duosporites é exclusivo do hemisfério austral. Todos os gêneros, à exceção de Calamospora, representam testemunhos da existência de várias licófitas, contribuindo para a formação do carvão Monte Mor. Calamospora, por sua vez, é atribuído às esfenófitas e noegeratiófitas.

Segundo Trindade (1970, p. 464), "Ós estudos de megásporos . . . apontam as seguintes famílias e habitus: Lepidodendraceae: habitus Lagenoisporites, Sigillariaceae: habitus Lagenoisporites, Bothrodendraceae: habitus Setosisporites, Selaginellaceae: habitus Setosisporites, Sphenophyllaceae: habitus Calamospora, Calamitaceae: habitus Calamospora, Noegerathiaceae: habitus Calamospora".

De uma certa forma, os macrofósseis da capa do carvão corroboram alguns dos habitus dos megásporos do carvão: na família Lepidodendraceae, os gêneros Lepidodendron e Lycopodiopsis; na família Sphenophyllaceae, o gênero Sphenophyllum; e, nas esfenófitas em geral, o gênero Paracalamites.

Segundo Trindade, a flórula responsável pelo depósito de carvão e folhelho carbonoso de Monte Mor deveria apresentar, no mínimo, 4 gêneros de licófitas e 1 de esfenófita. Encontramos, na capa do carvão, 2 licófitas, Lepidodendron e Lycopodiopsis, e 2 esfenófitas, Sphenophyllum e Paracalamites.

Para Trindade (1970, p. 460) os megásporos do carvão Monte Mor ". . testemunham, ainda a interdigitação das floras boreal e austral no Gondwana brasileiro", o que é corroborado pelos macrofósseis. Na mesma página, diz que esses megásporos "... sugerem a necessidade de reexaminar os macrofósseis de licófitas estudados por Barbosa e Almeida (1949), Barbosa e Gomes (1958) e Barbosa (1958). Outrossim, sugerem restringir ao Permiano a observação de Edwards (1952) e Kräusel (1961) de não existirem gêneros boreais de licófitas no Gondwana brasileiro". Mais uma vez, os macrofósseis vegetais da capa do 
carvão comprovam essa assertiva, ao fazermos a reabilitação do gênero Lepidodendron no Gondwana brasileiro, bem como da espécie de Zeiller, com emendas, $L$. pedroanum, que aparece em associação com outras licófitas tipicamente gondwânicas: Lycopodiopsis pedroanus e $L$. derbyi.

Finalmente, conclui Trindade (1970, p. 465), "Assim, parece-nos que a constelação de Monte Mor sugere, como idade, o Carbonífero Superior para os estratos em foco", o que é evidenciado, também, pelos macrofósseis.

A ocorrência, também, de concostráceos cf. Leaia nessa flórula reveste-se de especial significado. Sabemos da importância que têm esses crustáceos, dominantemente de águas doces, para a Paleontologia. A sua distribuição estratigráfica abrange o Neopaleozóico e, no Brasil, ocorria, até agora, no Grupo Passa-Dois do Estado de Santa Catarina. Para Mendes e Petri (1971, p. 100), "A presença de fáunulas marinhas especiais no Grupo Tubarão sotopostas e a ocorrência de Leaia - concostráceo que não ultrapassou o fim do Paleozóico - nas camadas superiores do Grupo Passa-Dois determinam a idade permiana deste último". Ora, a simples ocorrência de cf. Leaia, que é uma forma rara em Monte Mor, não permite, por si só, que se estabeleça para essa tafoflórula uma idade mais recente que Estefaniano. É mais razoável alterar-se sua distribuição estratigráfica de exclusivamente do Grupo Passa-Dois para o Grupo Tubarão, também.

Segundo Tasch (1969), várias observações sobre a Zona Leaiaídea da Antártida têm importância para as correlações gondwânicas, destacando-se entre elas o descobrimento de uma zona de Leaia na Formação Mount Glossopteris, da Cordilheira Ohio da Antártidà, ao lado das já conhecidas ocorrências da Formação Rio do Rasto do Brasil e do Beaufortiense Inferior de Natal, África do Sul; a aparição inicial dos leaiaídeos na Cordilheira de Ohio durante o Beaufortiense Inferior sugere uma origem não-antártica para os mesmos; os estudos paleomagnéticos situam, durante o Permo-Carbonífero, a Austrália contígua ou muito próxima da Antártida e, já que os leaiaídeos são abundantes no carvão de Newcastle, esta pode ser sua área de origem.

Conseqüentemente, a ocorrência de cf. Leaia nos níveis basais do Grupo Tubarão sugere ser essa região, na dependência de novas ocorrências mais abundantes e de estudos mais completos, inclusive paleomagnéticos, um provável centro de gênese e dispersão desses concostráceos no Gondwana, ficando o carvão .Newcastle, da Austrália, sob esse aspecto, num plano secundário.

Implicaçóes paleoecológicas Baseados no estudo dessa tafoflórula, na litologia dos estratos em que a flórula está situada e na bibliografia avaliável, fizemos algumas tentativas de conclusões concernentes às condições reinantes durante o tempo de deposição do carvão de Monte Mor e subseqüente deposição das plantas fósseis.

A reconstituição de um cenário terrestre, durante o Gondwana Inferior, foi feita por Seward (1941), Plumstead (1966) e Rigby (1969). Seward considerou-o como tendo uma vegetação esparsa próxima a uma cadeia montanhosa sob condiçōes glaciais. Plumstead admite uma vegetação mais luxuriante, embora próxima a altas cadeias montanhosas, com extensos vales glaciais. Para Rigby, o ambiente proposto por Seward não era favorável ao crescimento de plantas grandes, que existiram no Gondwana, concordando com a idéia de Plumstead, de uma vegetação mais luxuriante, pelo acúmulo da matéria vegetal, suficiente para a formação de carvão. Entretanto discorda desses autores quanto à proximidade dessa vegetação dos vales glaciais que, segundo ele, nunca existiram nas bacias marginais do Neopaleoźóico.

Para Rigby, a história da maioria dessas bacias carboníferas resumiu-se na seguinte sequêencia: um lençol de gelo desenvolvia-se, inicialmente, erodindo a área da bacia. Quando o gelo retraía-se, e muitas vezes desaparecia totalmente, a superficie mostrava um relevo 
como o de muitas áreas do hemisfério norte, que foram afetadas pela glaciação pleistocênica. Com o aparecimento de um clima temperado, desenvolviam-se, inicialmente, riachos irregulares, muitas vezes com formação de lagos. Quando a drenagem original se tornava senil, desenvolviam-se pântanos onde ocorria deposição de carvão límnico. Pela ocupação total do pântano, desenvolvia-se nova drenagem, podendo ter ocorrido, concomitantemente, uma mudança do nível pluviométrico. Embora o gelo glacial permanente estivesse ausente nessa época, era razoável que a área estivesse fria durante o inverno e, conseqüentemente, o gelo teria se formado, transitoriamente, sobre rios e lagos.

$\mathrm{E}$ conhecido o fato de que a maioria das madeiras silicificadas de Gimnospermas do Gondwana Inferior mostra evidências de anéis de crescimento. Esses anéis normalmente indicam variações climáticas anuais, devidas às alternâncias de temperaturas de verão e inverno ou, então, às mudanças entre estações secas e úmidas. Para Rigby, os caules licopodiais, descritos e figurados na África do Sul, Austrália e Brasil, constituem-se nas únicas plantas do Gondwana Inferior que têm indicações seguras de crescimento sazonal.

Segundo Rigby, as licófitas do hemisfério sul têm um hábito semelhante às do hemisfério norte, ainda que a maneira de ramificação não seja conhecida. Para ele, Lycopodiopsis cresce próximo ao limite superior de uma inundação normal.

Para a maioria dos autores, as folhas Sphenophyllum são de uma planta com hábito rasteiro. Entretanto, das plantas dominantes da época, foi o único gênero a desfrutar de distribuição universal no final do Paleozóico, e tal hábito, evidentemente, não se coaduna com tamanha distribuição. Rigby concebe-a, então, como uma pequena árvore mais afastada do limite superior de inundação. Outras esfenófitas, como Paracalamites, ficariam bem próximas das margens dos rios.

O gênero Sphenopteris tem sido mostrado como um feto grande, mas sem tronco característico, crescendo, provavelmente, em locais úmidos e ventilados. $O$ mesmo se pode dizer do hábito de Botrychiopsis, que, por sua raridade, faria parte do substrato de uma floresta de coniferas ou de Glossopterídeas.

$\mathrm{O}$ gênero Noeggerathiopsis, do hemisfério austral, é muito similar ao gênero Cordaites, do hemisfério boreal, e ambos são representados como grandes árvores com os ramos presentes somente na copa, na concepção de Grand'Eury (1877), ficando situados próximos de Sphenophyllum e um pouco afastados do limite superior de uma inundação normal. As com níferas, tipo Paranocladus, são mostradas sempre longe d'água e, algumas vezes, próximas às árvores das Glossopterídeas.

Do exposto, verificamos que o ambiente de formação do carvão Monte Mor e do ambiente subseqüente de deposição das plantas fósseis seria equivalente ao proposto por Rigby para os depósitos de Criciúma, Estado de Santa Catarina, e de Laras, Estado de São Paulo, respectivamente, dos grupos Tubarão e Passa-Dois.

Um ambiente aquoso límnico, representado por uma bacia lacustrina, é sugerido para o afloramento Sítio da Mina, em Monte Mor, pela presença de concostráceos cf. Leaia, de euripterideos cf. Eurypterus e de vegetais como Lepidodendron, Lycopodiopsis, Paracalamites, Sphenopteris, Cordaicarpus, Paranocladus, etc.

Provavelmente, tanto na formação do carvão Monte Mor, de um modo indireto, quanto na subseqüente deposição das plantas fósseis e das demais camadas da capa do carvão, perdurou, por um tempo relativamente longo, uma deposição tranquiila de sedimentos nessa bacia, trazidos pela drenagem de pequenos e irregulares riachos. Em apoio a essa sugestão, citamos o ritmismo observado nas camadas sedimentares do afloramento, onde, nas camadas (1) a (8), é visível a alternância de folhelho argilo-arenoso a argilito arenoso, na ausência de diastemas.

Dentro dessa tentativa de reconstituição ambiental, restam, ainda, dois pontos im- 
portantes para serem abordados: a origem do carvão de Monte Mor, que não é observável no afloramento e do qual só temos informações indiretas, e a presença, na tafoflórula, de elementos boreais.

É notório o fato de que, na conceituação paleopalinológica, os megásporos apresentam pouca mobilidade. Segundo Trindade (1970), os megásporos do carvão Monte Mor teriam sido originários de flora autóctone ou semi-autóctone da regiăo de depósito do carvão. Os macrofósseis vegetais, da capa do carvão, são bastante favoráveis à sugestão de Trindade já que se apresentam relativamente em boas condições de fossilização. Podemos acrescentar, entretanto, que a decorticação observada em todos os córtices caulinares de licófitas dessa tafoflórula pode indicar um transporte, cuja intensidade dependeria do volume d'água.

Se admitimos a drenagem local realizada por vagarosos e irregulares riachos, então, evidentemente, o transporte foi muito pequeno.

Quanto à presença de elementos boreais na Tafoflórula Monte Mor e em outras tafoflórulas gondwânicas, três explicações possiveis têm sido formuladas por diferentes autores:

1) as associações que contêm elementos boreais são mais antigas que as formadas por uma tafoflora "pura" de Glossopteris;

2) os taxa boreais desenvolveram-se independentemente, por homoplasia, no Gondwana;

3) os elementos boreais são verdadeiros imigrantes e estão localizados nas zonas marginais do Gondwana ou em zonas paleoclimáticas definidas que, durante o Permo-Carbonífero, estavam suficientemente próximas a outras massas continentais.

Para Archangelsky e Arrondo (1969), a primeira explicação baseia-se em alguns dados de fósseis marinhos da India, da Austrália e da América do Sul, segundo os quais os depósitos continentais do Gondwana Inferior pertenceriam mais ao Permiano Inferior do que ao Carbonífero. Entretanto, alguns taxa vegetais "nórdicos" parecem indicar o Carbonífero.

A segunda explicação apóia-se, até agora, em informações deduzidas das associações vegetais gondwânicas pré-permianas. Para esses autores, tais antecessores não são conhecidos, atualmente, nas tafofloras sul-americanas.

A terceira explicação, finalmente, sugere que algumas zonas marginais do Gondwana estavam suficientemente próximas de outras massas continentais, possibilitando uma migração durante o Carbonífero Superior ou Permiano Inferior. Ou, então, uma diferenciação zonal paleoclimática observada no hemisfério boreal deve ter existido, também, no Gondwana, podendo diferentes associações vegetais ter sido sincrônicas.

É visível, na Tafoflórula Monte Mor, que a Divisão Pteridophyta é a dominante entre os elementos cosmopolitas e boreais, quando comparada com a Divisão Gymnospermae. E muito bem conhecida sua adaptação a ambientes extremos e, por isto, seus elementos podem ser considerados como pioneiros em potencial nas migrações e dispersões entre associações florísticas.

Sua preservação, porém, é mais dificil, quando comparada com a Divisão Gymnospermae. Entretanto seus esporos são mais resistentes que os grãos de pólen e, evidentemente, têm indiscutíveis vantagens na dispersão. Entre eles os micrósporos, produzidos por plantas isósporas como as Marattiales e as Articulatales, têm um poder de dispersão bem maior que os megásporos, produzidos por plantas heterósporas como as Lycopsida arborescentes. Outros mecanismos de migração e dispersão favorecem muito mais as Pteridophyta que as Gymnospermae.

Portanto a presença de elementos boreais e cosmopolitas na Tafoflórula Monte Mor seria explicada por uma diferenciação zonal paleoclimática, nessa região, idêntica à obser- 
vada nas massas continentais boreais, permitindo a migração e a dispersão de elementos pioneiros em potencial de massas continentais próximas, onde os mesmos teriam um ambiente ideal de desenvolvimento. Hipotéticamente, elementos como Adiantites e Rhacopteris, do Carbonífero Inferior do Estado do Piauí, teriam, assim, alcançado a base do Carbonífero Superior do Estado de São Paulo.

Para Barbosa (1958, p. 231), "The intrusion of boreal elements into the Gondwana florulas, which developed during the interglacial epochs, shows that the ecological conditions for the formation of coal were not very different in both hemispheres. The two floras had only a different development and adaptation".

À medida que as condições paleoclimáticas foram se modificando, provavelmente, do sudeste para o sul do Brasil, muitos desses elementos, boreais e cosmopolitas, não encontraram mais ambiente propício para seu desenvolvimento e, naturalmente, a partir do Estefaniano não são mais encontrados em nossas tafoflórulas gondwânicas, representando a Tafoflórula Monte Mor, nạ transição Westfaliano-Estefaniano, o limite máximo de alcance de alguns desses elementos dentro do Gondwana Inferior da bacia do Paraná.

CONCLUSÓES O estudo dessa associação paleoflorística, sua comparação com outras tafoflórulas, a distribuição estratigráfica de seus elementos e as implicaçães paleoecológicas, permitem-nos as conclusões enumeradas a seguir.

1. É feita a reabilitação do gênero Lepidodendron no Gondwana brasileiro, restritamente ao Carbonífero Superior, e, com emendas da espécie de Zeiller, que relacionou seu material ao de Carruthers. Consideramos Lepidodendron pedroanum como espécie distinta de Lycopodiopsis pedroanus, baseados numa morfologia em que, na primeira espécie, são observados vestígios de paricnos e lígula, inexistentes na segunda. A presença dessa licófita boreal na Tafoflórula Monte Mor é corroborada pelos palinocênios do carvão Monte Mor, estudados por Trindade (1970).

2. Os palinocênios desse carvão sugerem restringir-se ao Permiano a observação de Edwards (1952) e Kräusel (1961) de que não existem gêneros boreais de licófitas no Gondwana brasileiro.

3. Ocorrência nessa associação paleoflorística, e pela primeira vez no Grupo Tubarão do Estado de São Paulo, de Lycopodiopsis derbyi, contrariando sugestão de Edwards (1952) de colocar essa espécie em sinonímia de $L$. pedroanus, que também ocorre em Monte Mor. Ocorrência, também, de uma nova forma de licófita, Lycopodiopsis sp. A. O estudo dos megásporos corroboram essa diversificação de licófitas em Monte Mor.

4. Ocorrência, pela primeira vez no Grupo Tubarão do Estado de São Paulo, das espécies: Trileites sp. (como impressões), Sphenophyllum sp. A, Paracalamites australis, Sphem nopteris sp. A, Botrychiopsis cf. plantiana, Noeggerathiopsis hislopii, Paranocladus? fallax, Buriadia heterophylla e Samaropsis seixasii.

5. Ocorrência, pela primeira vez no Gondwana Inferior do Brasil, das espécies: cf. Ginkgophyllum sp. A, Rhacopteris cf. chubutiana, R. cf. ovata,? Botrychiopsis cf. weissiana, Para calamites cf. levis, $P$. montemorensis, Cordaicarpus nitens e $G$. barbosanus.

6. Mais da metade das espécies de Monte Mor não são restritos à bacia do Paraná, isto é, são encontradas em tafoflórulas gondwânicas de outros países. Verificando-se a dism tribuição estratigráfica de seus elementos, essa associação paleoflorística revelou-se tipicamente carbonifera, pela reunião das Lycopsida e Sphenopsida arborescentes com Botry chiopsis, Rhacopteris, Adiantites, etc., na ausência das Glossopterídeas.

7. A presença de Lepidodendron na macroflórula implica duas conseqüências imediatas: corrobora os estudos dos palinocênios e dá um caráter essencialmente carbonífero à associação paleoflorística de Monte Mor, juntamente com os demais elementos. 
8. A presença de Botrychiopsis, nessa associação, permite-nos uma boa argumentação para o estabelecimento de uma idade relativamente antiga para a Tafoflorula Monte Mor, mais antiga que qualquer outra tafoflórula do Gondwana Inferior de nosso país.

9. Se essa idade estiver nos limites de uma transição Westfaliano-Estefaniano, sugerimos, então, o sudeste do Brasil como possível centro de gênese e de dispersão de Botrychiopsis plantiana, apoiando a idéia original de Harrington de que essa espécie teria alcançado seu nível estratigráfico mais inferior.

10. Conseqüentemente, o carvão Monte Mor, do Estado de São Paulo, é mais antigo que o carvão das bacias carboníferas do Estado do Rio Grande do Sul, cuja idade é admitida como estefaniana e onde Botrychiopsis ocorre mesclado com as Glossopterideas.

11. De uma certa forma, os macrofósseis da capa do carvão Monte Mor corroboram alguns dos habitus dos megásporos do carvão, citados por Trindade (1970): habitus Lageinosporites, pelos gêneros Lepidodendron e Lycopodiopsis e habitus Calamospora, pelo gênero Sphenophyllum.

12. Segundo Trindade, a flórula responsável pelo depósito de carvão e folhelho carbonoso de Monte Mor deveria apresentar 4 gêneros de licófitas e 1 de esfenófita. A associação da capa do carvão revelou 2 licófitas: Lepidodendron e Lycopodiopsis e 2 esfenofitas: Paracalamites e Sphenophyllum.

13. Os megásporos do carvão Monte Mor testemunham a interdigitação das floras boreal e austral no Gondwana brasileiro. A macroflórula da capa do carvão evidencia, também, esse fato, pela associação de elementos gondwânicos com elementos boreais e cosmopolitas.

14. A distribuição estratigráfica de Cordaicarpus nitens, em cuja sinonímia consta Eucerospermum nitens e E. patagonicum, encontrado até agora somente em Monte Mor, Brasil, e em Betancourt e Piedra Shotel, Argentina, é alterada exclusivamente do Permiano Inferior para o Carbonffero Superior, também.

15. A distribuição estratigráfica de Samaropsis seixasii é, também, mais antiga porque, até agora, sua ocorrência estava restrita à Tafoflórula Joaquim Branco, do Estado de Santa Catarina.

16. A distribuição estratigráfica do concostráceo Leaia em nosso país, em virtude de sua ocorrência em Monte Mor (cf.), é alterada exclusivamente do Grupo Passa-Dois para o Grupo Tubarão, também.

17. A ocorrência de cf. Leaia nos níveis basais do Grupo Tubarão pode significar, na dependência de novas ocorrências de estudos mais completos, que essa região constituiu-se, provavelmente, num centro de dispersão desses concostráceos no Gondwana, ficando o carvão Newcastle da Austrália, sob esse aspecto, num plano secundário.

18. A ocorrência do euripterídeo cf. Eurypterus em Monte Mor é importante porque corrobora o habitat de água doce para esse artrópode quelicerado, pela associação com o concostráceo cf. Leaia e com os vegetais descritos e, também, porque é a segunda ocorrência de um euripterídeo no Grupo Tubarão do Estado de São Paulo onde, até agora, somente Hastimima tinha sido assinalado por Mezzalira (1951).

19. O ambiente de formação do carvão Monte Mor e o da subseqüente deposição das plantas fósseis teria sido equivalente ao proposto para os depósitos de Criciúma, Estado de Santa Catarina, e de Laras, Estado de São Paulo, por Rigby (1969).

20. Em Monte Mor, um ambiente aquoso límnico, representado por uma bacia lacustrina, é deduzido pela presença do concostráceo cf. Leaia, do euripterídeo cf. Eurypterus e de vegetais como Lepidodendron, Lycopodiopsis, Paracalamites, Sphenopteris, Paranocladus, Cordaicarpus, etc.

21. Com base nos megásporos, é bem provável uma origem semi-autóctone do carvão 
Monte Mor. Os macrofósseis da capa do carvão apresentam-se, relativamente, em boas condições de fossilização, embora com córtices caulinares de Lycopsida bem decorticados e, com base neles, é muito difícil qualquer sugestão nesse sentido.

22. Provavelmente, tanto na formação do carvão Monte Mor, quanto na deposição subseqüente das plantas fósseis e das outras camadas, o ambiente de deposição dos sedimentos foi tranqüilo, pelo ritmismo observado nas camadas de folhelho argilo-arenoso a argilito-arenoso, na ausência de diastemas.

23. Finalmente, a presença de elementos boreais e cosmopolitas em Monte Mor poderia ser explicada por uma diferenciação zonal paleoclimática, que ali ocorreu durante - Carbonífero Superior, idêntica à observada nas massas continentais boreais, permitindo a migração e a dispersão de elementos pioneiros em potencial de massas continentais próximas, onde o ambiente de seu desenvolvimento teria sido mais favorável. A ausência de alguns desses elementos, por outro lado, nas tafoflórulas gondwânicas do sul do Brasil poderia ser explicada pela modificação das condições paleoclimáticas, provavelmente na direção sudeste-sul, durante o Permo-Carbonífero. A Tafoflórula Monte Mor, na transição Westfaliano-Estefaniano, representa, portanto, o limite máximo de alcance de alguns desses elementos dentro do Gondwana Inferior da bacia do Paraná.

Agradecimentos Minha profunda gratidão à Cleusa e à Giselle, esposa e filha dedicadas, em quem sempre encontrei apoio, ânimo e compreensão. À minha querida sogra e a meu inesquecível pai, a cuja memória dedico este trabalho.

Aos professores Dr. Viktor Leinz, Dr. Setembrino Petri, Dr. Antônio Carlos Rocha-Campos e Dr. Elias Dolianiti, pelas valiosas sugestões oferecidas.

Minha gratidão ao Prof. Dr. Josué Camargo Mendes, do Instituto de Geociéncias da Univer* sidade de São Paulo, não apenas pela orientaçăo dada na tese de doutoramento, mas também pelo seu constante apoio e estímulo.

Ao Conselho de Ensino para Graduados da Universidade Federal do Rio de Janeiro e ao Conselho Nacional de Pesquisas, pelos auxílios recebidos. À Comissão Permanente de Tempo Integral e Dedicação Exclusiva, pelo apoio, que possibilita maior dedicação às atividades docentes.

\section{BIBLIOGRAFIA}

ARCHANGELSKY, S. - 1965 - Tafolloras paleozóicas y eomesozoicas de Argentina. Soc. Argent. Bot., Bol. 10 (4): 247-291

ARGHANGELSKY, S. - 1968 - Permskie i triasovye flory Juznoi Ameriki. Trud. Geol. Inst. Akad. Nauk S.S.S.R., 191: 71-87

ARCHANGELSKY, S. e ARRONDO, O. G. - 1969 - The Permian taphofloras of Argentina with some considerations about the presence of "northern" elements and their possible significance. IUGS Symp., Buenos Aires 1-15 october 1967, Gondw. Strat., pp. 71-90, UNESCO, Paris

ARCHANGELSKY, S. e ARRONDO, O. G. - 197l a - Palaeophytologia Kurtziana III. I. Notas sobre los vegetales carbonicos y permicos de la Coleccion Kurtz. Ameghiniana, 8 (3-4): 181-188, Buenos Aires

ARCHANGELSKY, S, e ARRONDO, O. G. - 1971b - Palaeophytologia Kurtziana III. 2. Estudio sobre el género Botrychiopsis Kurtz (Gondwanidium Gothan) del carbónico y pérmico gondwanico. Ameghiniana, 8 (3-4): 189-227, Buenos Aires

ARCHANGELSKY, S. e LEGUIZAMON, R. R. - 1971 - Vojnovskya argentina n. sp. nueva gimnosperma del carbónico superior de Sierra de los Llanos, Prov. La Rioja. Ameghiniana, 8 (2): 65-72, Buenos Aires

ARRONDO, O. G. - 1971 - Palaeophytologia Kurtziana III. 3. Rhacopteris sjanochai Kurtz de la Formacion Jejenes (Carbonico Superior), San Juan. Ameghiniana, 8 (3-4): 228-230, Buenos Aires

BARBOSA. O. e ALMEIDA, F. F. M. de - 1949 - A Série Tubarão na bacia do rio 'Tietê, Estado de São Paulo. Div. Geol. Miner., D.N.P.M., Notas Prelim. Estudos, 48: 1-16, Rio de Janeiro 
BARBOSA, O. - 1958 - On the age of the Lower Gondwana floras in Brazil and abroad. XX Congr. Geol. Int., pp. 205-236, México

CUERDA, A. J., WAGNER, R. H. e ARRONDO, O. G. - 1968 - Observaciones sobre algunas floras del Carbonífero argentino. Ameghiniana, 5 (7): 265-269, Buenos Aires

DAEMON, R. F, e QUADROS, L. P. - 1970 - Bioestratigrafia do Neopaleoz6ico da bacia do Paraná. Soc. Bras. Geol., Anais XXIV Gongr. Bras. Geol., pp. 359-412, Brasília

DOLIANITI, E. - 1953 - Considerações sobre a presença de Gondwanidium plantianum no Rio Grande do Sul. An. Acad. brasil. Ciênc., 25 (2): 126-132, Rio de Janeiro

EDWARDS, W. N. - $1952-$ Lycopodiopsis, a Southern hemisphere lepidophyte. Palaeobotanist, i : 159-164, Lucknow

GRAND'EURY, C. - 1877 - Flore carbonifère du Département de la Loire et du centre de la France. Mem. Acad. Sci. Inst. France, 24: 208-220, Paris

HARRINGTON, H. - 1934 - Sobre la presencia de restos de la Flora de "Glossopteris" en las sierras australes de Buenos Aires. Rev. Museo La Plata, 34: 303-338, La Plata

KRAUSEL, R. - 1961 - Lycopodiopsis derbyi Renault und sinige andere Lycopodiales aus dem Gondwana-Schichten. Palaeontographica, 109: 62-92, Stuttgart

MENDES, J. G, e PETRI, S. - 1971 - Geologia do Brasil - Inst. Nac. Liv., Enc. Bras., Geol., vol. 9, 207 pp., Rio de Janeiro

MEZZALIRA, S. - 1951 - Ocorrências do Euripterídeo Hastimima no Estado de São Paulo. Div. Geol. Miner, D.N.P.M., Notas Prelim. Estudos, 52: 1-14, Rio de Janeiro

MILldAN, J. H. - 1972a - Macroflórula Carbonífera de Monte Mor, Estado de São Paulo. Tese de Doutoramento, Inst. Geoc., Univ. São Paulo, 165 pp., Såo Paulo

MILLAN, J. H. - 1972b - Lower Gondwana macroflorula from Monte Mor, State of São Paulo, Brazil. Int. Symp. Carbon. Perm. Syst. S. Amer., Abstract 35, São Paulo

PLUMSTEAD, E. P. - 1966 - The story of South Africa's coal. Optima (Dec. 1966), pp. 186-202, Johannesburg

RIGBY, J.F. - 1969 - The Lower Gondwana Scene. Bol. Paranaense Geoc., 27: 3-14, Guritiba

RIGBY, J. F. - 1970 - The distribution of Lower Gondwana plants in the Paraná basin of Brazil. Proc. Gondw. Symp., pp.575-584, Pretoria

ROCHA-CAMPOS, A. C. - 1972 - Late Paleozoic Geology of Northern Paraná Basin. Int. Symp. Garbon. Perm. Syst. S. Amer, Exc. Guide-Book, 68 pp., São Paulo

SEWARD, A. C. - 1941 - Plant life through the ages. A geological and botanical retrospect. Cambridge Univ. Press., 607 pp., Cambridge

SURANGE, K. R. - 1966 - Indian fossil Pteridophytes. Bot. Monogr., vol. 4, 209 pp., Nova Délhi

TASCH, P. - 1969 - Antarctic Leaiid Zone: seasonal events: Gondwana correlations. IUGS Symp., Buenos Aires 1-15 october 1967, Gondw. Strat., pp. 185-196, UNESCO, Paris

TRINDADE, NICÉA M. - 1970 - Megásporos Carboníferos de Monte Mor, Estado de São Paulo. An. Acad. brasil. Giênc., 42 (3): 415-420, Rio de Janeiro 